Vol. 16, $n^{\circ} 2$ | 2012

Varia

\title{
David J. Cox, A Certain Share of Low Cunning. A history of the Bow Street Runners, 1792-1839
}

Cullompton-Portland, Willan Publishing, 2010, 280 p. ISBN

978-1-84392-773-0.

\section{Catherine Denys}

\section{(2) OpenEdition}

Journals

Édition électronique

URL : http://journals.openedition.org/chs/1370

DOI : $10.4000 /$ chs. 1370

ISSN : 1663-4837

Éditeur

Librairie Droz

Édition imprimée

Date de publication : 1 décembre 2012

Pagination : 113-114

ISBN : 978-2-600-01642-1

ISSN : 1422-0857

Référence électronique

Catherine Denys, «David J. Cox, A Certain Share of Low Cunning. A history of the Bow Street Runners, 1792-1839», Crime, Histoire \& Sociétés / Crime, History \& Societies [En ligne], Vol. 16, n² | 2012, mis en ligne le 13 mars 2013, consulté le 22 septembre 2020. URL : http://journals.openedition.org/chs/1370 ; DOI : https://doi.org/10.4000/chs.1370

Ce document a été généré automatiquement le 22 septembre 2020

(C) Droz 


\section{David J. Cox, A Certain Share of Low Cunning. A history of the Bow Street Runners, 1792-1839}

Cullompton-Portland, Willan Publishing, 2010, 280 p. ISBN

978-1-84392-773-0.

\section{Catherine Denys}

\section{RÉFÉRENCE}

David J. Cox, A Certain Share of Low Cunning. A history of the Bow Street Runners, 1792-1839, Cullompton-Portland, Willan Publishing, 2010, 280 p. ISBN 978-1-84392-773-0.

1 Ce livre s'insère dans le développement des études historiques sur la police en se penchant sur les Officiers Principaux de police du bureau de Bow Street, plus connus sous le sobriquet de «Bow Street Runners ». Quoique la création de Bow Street par Henry Fielding remonte à 1748, l'étude commence avec le Police Act de 1792 qui crée sept autres bureaux sur le même modèle dans Londres. L'approche est doublement originale, en ce que David Cox attire l'attention sur la différence, rarement bien établie, entre ces Officiers Principaux et leurs collègues de rang moins élevé, principalement affectés aux patrouilles; et aussi en ce qu'il s'intéresse essentiellement aux missions confiées à ces Officiers Principaux hors de la métropole. Les archives laissées par l'activité du bureau de Bow Street étant assez maigres, l'auteur s'est appuyé sur la presse et les archives des tribunaux pour retrouver 601 affaires en province et 292 dans la capitale.

2 Les trois premiers chapitres sont consacrés à la description du cadre de travail et du groupe social des Officiers Principaux de Bow Street. David Cox se montre très soucieux de réhabiliter la réputation de ces hommes, prouvant efficacement que l'accusation générale de corruption à leur égard est infondée. En réalité, la condamnation morale des agents de Bow Street relève davantage d'une réprobation générale à l'égard d'un 
système policier et judiciaire vénal. Il serait sans doute possible d'aller un peu plus avant, pour interpréter cette réprobation comme la marque d'une exigence croissante de séparation entre services publics et services privés demandés à la police, dans un mouvement de fond qui ne concerne pas seulement la Grande-Bretagne. Plus qu'une démonstration ponctuelle basée sur les affaires les plus célèbres de corruption policière, une étude quantifiée de la part des récompenses privées et des salaires ou primes délivrés par les institutions publiques aurait permis d'approcher plus précisément la question. De même, la question de la situation dans l'échelle sociale des 35 Officiers Principaux mériterait un traitement systématique, plutôt que de se limiter à quelques célebrités dont le parcours semble exceptionnel.

3 Les deux chapitres suivants démontrent la variété des crimes dans lesquels les compétences des Officiers Principaux sont utilisées, depuis l'enquête sur des meurtres jusqu'à l'infiltration dans les mouvements sociaux qui menacent l'ordre établi ; ainsi que l'extension géographique de leurs interventions. Le recours aux hommes de Bow Street s'explique notamment lorsque les forces de l'ordre locales sont trop proches des populations délinquantes, ou trop absorbées par leurs multiples fonctions quotidiennes, pour être efficaces. Une différence apparaît nettement entre la province où les Officiers Principaux sont essentiellement employés par les riches propriétaires qui peuvent rémunérer leurs services coûteux pour des enquêtes longues et complexes, alors que les vols constituent le quotidien des officiers à Londres. Le chapitre 6, quant à lui, donne un aperçu des méthodes innovantes employées par les Officiers Principaux, au cours de six études de cas différents. Enfin le chapitre 7 évoque la survie étonnante du service après la création de la Police Métropolitaine, jusqu'à sa disparition sans éclat en 1839.

En portant l'éclairage sur cet aspect peu connu des activités de Bow Street, David Cox ne se contente pas de remplir une case vide de l'histoire pourtant abondante de la police britannique. Il propose aussi une révision historiographique, en démontrant que les «Bow Street Runners » n'étaient pas un «cul-de-sac» de l'histoire, une tentative avortée et sans avenir, mais bien la préfiguration de la Detective Branch de la Police Métropolitaine créée en 1842. Les détectives courageux, intelligents et tenaces que décrit, avec une affection sous-jacente David Cox, doivent donc prendre place dans la longue chaîne des innovations peu visibles, mais essentielles, d'une modernisation de la police engagée dès le XVIII ${ }^{e}$ siècle. Les Officiers Principaux de Bow Street tournent en effet délibérément le dos à une police préventive traditionnelle pour se consacrer exclusivement à une police de détection dont ils sont, à cette époque, les seuls spécialistes, sur l'ensemble du pays. En cela le livre de David Cox, malgré quelques répétitions du propos et une vision étroitement britannique, constitue une œuvre importante qui s'inscrit dans le renouveau actuel des études sur l'histoire des polices «pré-modernes". 


\section{AUTEURS}

\section{CATHERINE DENYS}

IRHIS-Lille3

catherine.denys@univ-lille3.fr 